\title{
The Effectiveness of a Strategy Based on the Concepts of a Growth Mindset for Teaching Carpentry and Decoration in Developing Practical Vocational Skills and Imaginative Thinking
}

\author{
Adnan Said Ahmad AL-Husaini ${ }^{1} \&$ Eman Abdlfatah Amayreh ${ }^{2}$ \\ ${ }^{1}$ Department of Practical Studies, Ministry of Education, Kuwait, Kuwait \\ ${ }^{2}$ Al-Ahliyya Amman University Schools, Amman, Jordan \\ Correspondence: Adnan Said Ahmad AL-Husaini. E-mail: dr.aszasz@gmail.com
}

Received: January 17, 2021

Accepted: February 23, 2021

Online Published: March 31, 2021

doi:10.5539/ass.v17n4p1

URL: https://doi.org/10.5539/ass.v17n4p1

\begin{abstract}
This study aimed to investigate the impact of a strategy based on the concepts of growth mindset for teaching carpentry and decoration on developing practical professional skills and imaginative thinking among ninth grade students in the State of Kuwait. The study followed the semi-experimental approach. To achieve the objectives of the study, an observational checklist for practical vocational skills was prepared, consisting of (18) skills, and a test was prepared to measure the imaginative thinking skills of the sample members consisting of (10) essay questions. The study was applied to a sample of (51) students and they were divided randomly into two groups. Experimental, with (26) students, a control, (25) students. The study found a statistically significant effect of teaching with a strategy based on the concepts of growth mindset in improving practical professional skills and developing imaginative thinking skills.
\end{abstract}

Keywords: concepts of growth mindset, practical professional skills, imaginative thinking

\section{Introduction}

Vocational education as the field that consists of knowledge, skills and trends, and these aspects can only be mastered through training and creating training programs. Since vocational education is the total effort for education, no individual can but have a profession, this profession can only be correct by get training on it. Thus, the scientific and professional aspect has contributed to the development of societies on various levels as a scourge. Vocational education has taken its importance from its goals by addressing psychological problems by reinforcing the required behavior, and here is the role of the teacher who can be the trainer mainly after he has previously trained (Gonçalves, Dias, \& Peralta, 2018).

Vocational education is one of the subjects that include knowledge, skills and trends, and it is one of the subjects that aim to build an integrated personality. In other words, the function of this education is to build a person's mind, skill and behavior. From the mental point of view, it guides the human being to search for knowledge from its sources in order to employ it procedurally. On the skill level, the student works to acquire it through application and experimentation, so the skill becomes easy to be practiced it in a practical way. From the behavioral point of view, the student engages in a positive way in the performance of various vocational education activities (Ayesh, 2009).

\subsection{Theoretical Review}

The vocational education in its various curricula consists of basic components: inputs, processes, and outcomes or outputs. As for the inputs, they include the desired goals or products, and the student with his various developmental characteristics, in which he is the concerned person in the learning and teaching processes, exercises his role here as a researcher and as a young scientist. Among the vocational education inputs also the classroom environment and what it is supposed to represent in the information age, as this environment is based on creativity, collaborative work and excellence. The second component represented by the processes that include planning for education and choosing teaching methods, which the teacher adopts to achieve goals. The processes also contained preparing the educational learning condition, as well as evaluation strategies and tools. As for the outputs in vocational education, they are strongly and solidly linked to the planned goals in the 
cognitive, emotional and skill areas. However, the holistic view of these components remains very important in the mind of each component in its condition, in order to achieve quality in the outputs in particular. Among the most prominent outcomes of vocational education is the preparation of graduates armed with special skills to be employed in the labor market (Metzlera \& Woessmann, 2012; Ayesh, 2009).

One of the areas of vocational education in the curricula of the State of Kuwait is the field of carpentry and decoration. It is one of the areas of activities based on skill and accuracy. It is one of the finest arts known to mankind for its great practical benefits. The student in the ninth grade learns this field in several stages: making measurements on wood, sawing wood to prepare the product, conducting removing and filtering operations, conducting industrial processes, final assembly of the product, preparing the product for finishing operations, completing the finishing operations, and final output of the product.

Each of these stages has special practical vocational skills that students must possess. The levels of practical skill differ in terms of the levels of mental-muscular coordination required for it, as the skill levels range from the simple cognitive side, through the traditional responses to the originality in performance, through which the professional systems have developed. This because the student is not expected to modify designs, or produces original products, without mastering the basic skills in the systems with which he deals and seeks to develop them (Zaitoun, 2005).

Therefore, having practical skills is closely related to the mental abilities of the student. Thus, it is imperative to focus on the mental abilities and thinking skills of students when teaching vocational skills related to carpentry and decoration. One of the thinking skills that must be taken into account when teaching students in general, and teaching carpentry and decoration in particular, are imaginative thinking skills.

Samli (2011) defined imaginative thinking as a mental activity represented by the gathering of mental images resulting from linking data and lived effects with previous experiences. Accordingly, the researcher believes that in order to develop imagination skills, the student must be given the opportunity to retrieve previous experiences stored in his cognitive structure, by providing educational situations and activities rich in stimulating imagination. Gilman (2008) confirms this, as he believes that the imagination can be practiced by the individual in his mind continuously, and at any time, when he begins to create an image in the mind, and includes it in many details, for example, he imagines a bicycle with a better seat.

Imagination has many benefits for the student, including helping him build an expanded knowledge base, helping him to make symbols and concepts meaningful to him, enabling him to convert abstract ideas into sensory images that are easy for him to deal with, and helping him make difficult material easier and easier. It is a way to improve his memory, and get recovering Knowledge faster, as well as developing creative thinking (Qara \& Saifi, 2011).

Khawaldeh and Nasr (2019) believe that imaginative thinking includes the following skills:

- The skill of recognizing the contents and ideas in the text, which is known as the preparation of imaginative mental images of ideas and events, as these mental images can simulate reality, and enable the student to formulate new meanings. It evidenced this skill availability by indicators of following behavioral following: Recalling basic audio information and data and paying attention to its details, retrieving and describing previous images and experiences related to the audio, and evoking mental images of elements related to your experiences, events and places you have not seen before.

- The skill of understanding and discerning ideas and contents and the relationships between them: This skill is represented by the student's ability to think in an unfamiliar way, in order to be able to distinguish between the different ideas and the relationships between them, and here the non-attitudes of ideas are unleashed. This skill is evidenced by the availability of the following behavioral indicators: Explanation of ambiguous concepts and ideas with common and known examples, clarifying an ambiguous idea by placing it in an artistic template brings it closer to the tangible, and the distinction between the familiar and the unfamiliar in the audio material, by identifying the basic components and interfering factors.

- Transformational visualization skill: This skill means prediction, correlation and synthesis, as the student transforms images into new forms, and relates them to the realities of his daily life. Here, the imagination plays the role of a mediating aid. Evidenced this skill availability by the following behavioral indicators: propose amendments and additions to the images and ideas unfamiliar to become familiar, and to express abstract ideas with examples from everyday life and bring them closer to the significant, express his thoughts and feelings using strong words and examples of everyday life, decorate speech pictures and technical diagrams using images Integrated. 
- Creative imagination skill: This skill refers to recombination and synthesis. It is an active imagination more than just daydreams. It is a mastered and refined imagination, as it includes imagining original things. This skill is evidenced by the availability of the following behavioral indicators: suggesting possible and realistic reasons for a problem or phenomenon within the limits of his abilities, and providing unfamiliar solutions to an existing or hypothetical problem, as well as by translating meanings and ideas.

It is possible to develop students' performance in general, and to develop practical vocational skills and imaginative thinking for them in particular, through their continuous training of what is new and useful, including focusing on the concepts of a growth mindset.

A growth mindset is the belief that intelligence can be developed through effort, and that a person with a growth mindset believes that they are able to develop his capabilities over time, effort, and diligence. People with a growth mindset become lifelong learners, and when they face challenges, they appear to be more resilient than those with a fixed growth mindset (Yettick 2016). On the other hand, people with a stable growth mindset believe that they are unable to develop their own intelligence. This belief has negative effects on their development, effectiveness, and educational attitude, as they focus on the level of intelligence more than their participation in effective cognitive practices and problem-solving skills. They believe that they are unable to control their success or failure because they are determined by a fixed level of intelligence, moreover; They believe that talent alone can help a person succeed, and without effort, when teachers help students develop a growth mindset, they at the same time encourage students to develop the determination and passion needed to achieve long-term goals (Mejia, 2019).

Teaching growth mindset development strategies to students includes dealing with four categories that affect a student's self-efficacy. This includes performance achievement, indirect expectations, social persuasion and physiological states (Bandura, 1997). Teachers can present meaningful challenges and experiences to develop a growth mindset. Challenging learning can influence the growth of a student's self-efficacy by providing performance experiences in which the student achieves success. In addition, educational assignments may provide experiences of what the student may learn from his peers and provide opportunities for positive social persuasion through which the teacher can provide positive feedback. Challenging learning tasks can produce a positive physiological learning environment in which a student is less afraid of making mistakes.

Students see failure differently. A student with a growth mindset sees failure as an opportunity for growth (Dweck, 2015). Bandura (1997) suggests that students' perceptions of self-efficacy decline when they experience failure. With self-efficacy, all students see failure as a negative experience because it makes their capabilities questionable. When students develop a growth mindset and even in failure, they believe that they are able to develop their minds with effort and work, thus developing their self-efficacy and motivation to learn.

Duckworth, Peterson, Matthewz and Kelly (2007) argue that a growth mindset can develop traits such as determination and passion to achieve long-term goals. To achieve this, students need self-esteem and feedback that enhances this and develops intelligence. According to Yeager \& Dweck (2012), students need growth mindsets that present challenges. This can be done through new learning strategies, learning, help from others, and patience. Determination is the basis for success in school life when the student is exposed to challenges, whether in his academic or social life, and when the student faces Challenges, the level of determination has a significant impact on their desire to face these challenges (Mejia, 2019).

Dweck (2006) believes that the growth mindset encourages a love to learn status, especially in difficult situations, which increases the self-efficacy of the student. Bandura \& Dweck (1985) formulated the gradual theory and the theory of being (now known as the growth mindset and the fixed growth mindset). Incremental learning theory helps learners develop a growth mindset through the conscious transformation of their worldview from the belief that intelligence is fixed to the belief that intelligence is flexible and can be developed and increased through effort, determination, passion, and self-development (Lewis, Williams \& Dawson, 2020).

Conversely, the theory of being impedes a growth mindset by not practicing learning opportunities because students believe that failure and mistakes mean judging their inability. When a student goes through his life, challenges increase due to the change in the nature of the programs, the increase in the complexity of the curriculum, the tests, and the changes in the environment, even if the student is from those with a fixed growth mindset strive to appear smart without facing risks and challenges (Rissanen, Kuusisto, Tuominen \& Terri, 2019; Mullarkeya \& Schleider, 2020).

Dweck (2015) identifies a set of traits for people with a growth mindset, including:

1. They believe that their talents and capabilities are subject to development. 
2. Their energies can be fruitful through effort, perseverance and proper teaching.

3. They believe that people's capabilities and intelligence vary, and that their development is achieved through work, motivation, passion and love of learning.

4. Through growth mindset, he can learn important skills such as research, exploration, and investigation.

Dweck (2015: 6) also pointed out a set of rules for how a growth mindset works and how to activate it. These rules are:

1. the most important rule of a growth mindset is learn, learn and learn.

2. Work with passion and drive, as effort is the main key to development and creativity.

3. Deal with your mistakes realistically and address your weaknesses. Enhance your strengths with study, effort and training.

\subsection{Study Problem and Its Questions}

The study problem stems from the researcher's feeling, by virtue of his supervisory experience in practical studies and teaching carpentry and decoration in the State of Kuwait, as the researcher sought weakness in the practical professional skills of students. Also, as students always complain about the difficulty of applications in carpentry and decoration books. It was also observed that they had a weakness in imaginative thinking, as it was noticed that they had difficulty imagining products and designs in the event that they were mentioned verbally. Thus, the researcher sees the importance of adopting modern strategies for teaching carpentry and decoration, and more specifically, the study sought to answer the following questions:

1. Is there a statistically significant difference at the level of $(\alpha=0.05)$ between the mean scores of the students in the experimental group and the students in the control group in the practical vocational skills observation card attributed to the teaching method (strategy based on concepts of growth mindset, the usual teaching method)?

2. Is there a statistically significant difference at the level of $(\alpha=0.05)$ between the mean scores of the students in the experimental group and the students in the control group in the imaginative thinking scale due to the teaching method(strategy based on concepts of growth mindset, the usual teaching method)?

\subsection{Study Importance}

The importance of this study stems from its provision of a training program for students based on the concepts of a growth mindset to teach carpentry and decoration. The study also provides some metrics that can be used to find out students 'practical vocational skills and imaginative thinking. It also benefits those responsible for writing carpentry and decoration books, by providing them with feedback on the existing books and how to improve them with modern teaching strategies.

\subsection{Conceptual and Procedural Definitions}

The study adopts the following definitions:

- Growth mentality: it is a self-perception of the self that refers to the individual's perception that he is an intelligent person who is able to think, grow and otherwise. As an example, for such definition that the teacher's perception of himself or the father's perception of himself and so on. (Kiger, 2017). Procedurally, it is defined as the student's self-perception of his ability to think and the extent of improving his learning practices and developing his skills.

- Practical vocational skills: It is the series of observable practical movements, procedures, or performance steps that the ninth grade student performs while performing a specific task in carpentry and decoration work, and was measured procedurally in this study with the observation card that was specially prepared for this purpose.

- Imaginary thinking skills: Liang (2012) defined it as a mental process based on establishing relationships between experiences, organized in a mental representation of something or event that does not exist, and through the imagination, images are transformed from the imagined memory, and they are shown in the form of existing and other things. It does not exist, and the imagined uses the past to bring the imagined images, with the need to be enlightened by the present. It is measured by the degree achieved by the student by his answer on the scale of imaginative thinking skills prepared for the purposes of the current study.

\subsection{Study Limits}

- Humanitarian limits: It is the ninth-grade students.

- Spatial limits: Mubarak Al-Kabeer Governorate in the State of Kuwait. 
- Time limits: the first semester of the 2019/2020 academic year.

- The results of the study are determined by the validity and reliability of the two study tools, and the objectivity of the respondents.

\section{Method and Procedures}

\subsection{Study Approach}

The study used the semi-experimental approach with two groups (a control group, an experimental group, and a pre and post test), in order to suit this approach to achieve the objectives of the study.

\subsection{Sample of the Study}

The researcher chose the individuals of the study from Eid Badah Al-Mutairi School by the intentional method, since the researcher supervises those schools, and the experiment can be easily applied. Two divisions were appointed from the ninth grade basic class, one of which represented the experimental group (26) students, and the other represented the control group (25) students.

\subsection{Study Tools}

The present study requires the preparation of two tools:

\section{First: Observational checklist for practical vocational skills}

An observational checklist was prepared aiming to measure students' possession of practical vocational skills. With using the educational literature related to the topic of practical skills in the field of vocational education. The list was built according to a sliding scale as follows: very high (5), high (4), medium (3), weak (2), and non-existent (1).

The observational checklist were divided into (18) skills illustrated as the following: Preparing the workplace, observing public safety rules, maintaining equipment and tools, standing in the right place and shape, taking into account the economic aspects, taking measurements accurately, carrying out the deployment operations correctly, conducting removing and filtering appropriately, accurate final assembly, preparation of finishing works, appropriate finishing, use of appropriate materials, accuracy of final output of the product, addition of complementary materials, consideration of the aesthetic, product quality and perfection, cleanliness and arrangement the workplace after the completion, familiarity with the first aid skills primary.

Validity of observational checklist

The scale was presented to a group of curriculum and teaching professors, and to a specialist in tests and metrics, as these professors made some amendments to the texts of some paragraphs. The researcher approved the Referees' agreement at a rate of (80\%), including: Separating knowledge of safety and security rules from knowledge of first aid skills. Thus, the tool took its final form, and was made up of (18) practical skills.

Stability of observational checklist

To find out the stability of the note card, an exploratory sample was chosen from outside the study members, and consisted of (15) students, as the exploratory sample was observed, and the method of analysis and re-analysis was used after a period of two weeks. It was analyzed by another party (teacher) and compared both analyzes, according to Holsti equation reached (0.84), which confirms the stability of this tool.

Second: The imaginative thinking test

A test was built to measure imaginative thinking skills after referring to the theoretical literature related to the topic. The subject of (inspection and measurement) was chosen from the topics of carpentry and decoration, where students get benefit by answering to the paragraphs of the test for imaginative thinking skills. One essay question is devoted to each of the following imaginative thinking indicators:

- Bringing up mental images of elements related to people, events and places not seen before.

- Rearranging events and ideas in light of the sequence of events.

-Thinking about what is known to achieve something unknown.

- The ability to return to the flow of the thought chain in the event of distraction.

- Distinguish between the familiar and the unfamiliar.

- Explain vague concepts and ideas with common examples.

- Introducing proposals for modifications and additions to unfamiliar images and ideas, to make them familiar. 
- Expressing abstract ideas with examples from everyday life and approximating them to the sensible.

- Suggest realistic and probable causes for a problem.

- Offering unfamiliar solutions to an existing or hypothetical problem.

Two scores were assigned to each skill, bringing the total score of the test to (20) points.

Validate the imaginative thinking test

To verify the validity of the test, it was presented to a group of controls themselves, who put some notes on some of the test items, where the researcher took them all to form the final frame.

The imaginative thinking test stability

To verify the stability of the test, it was applied to the same sample, where the test was applied twice with an interval of two weeks. Using the Pearson correlation coefficient, a test reliability coefficient was extracted, which reached (0.86), and this reliability factor was acceptable for the purposes of the current study.

\subsection{Study Variables}

The study dealt with the following variables:

1- Independent variable: teaching method, it has two levels: the regular method, and the strategy of the concepts of growth mindset.

2- Dependent variables: It included practical vocational skills, and imaginative thinking skills.

\subsection{Statistical Process}

To answer the study questions, arithmetic means, standard deviations, and covariance analysis were extracted.

\section{Study Results and Discussion}

The first question: Is there a statistically significant difference at the level of $(\alpha=0.05)$ between the mean scores of the students in the experimental group and the students in the control group in the practical vocational skills observation card attributed to the teaching method (strategy based on concepts of growth mindset, the usual teaching method)?

To answer the study's first question, pre, post, and modified arithmetic averages and standard deviations and adjusted subjects of the study were extracted among the study subjects, as shown in Table 1.

Table (1). The pre, post, and modified arithmetic averages, deviations and standard errors of students' performance on the practical vocational skills observation card for the experimental and control groups

\begin{tabular}{ccccccc}
\hline \multicolumn{2}{c}{ modified } & \multicolumn{2}{c}{ post } & \multicolumn{2}{c}{ pre } \\
\hline SD & $\mathrm{M}$ & $\mathrm{SD}$ & $\mathrm{M}$ & $\mathrm{SD}$ & $\mathrm{M}$ & Group \\
0.80 & 9.10 & 2.31 & 9.47 & 2.07 & 7.38 & Control \\
0.65 & 12.88 & 1.98 & 13.84 & 2.28 & 8.29 & Experimental \\
\hline
\end{tabular}

It is clear from Table 1 that there are apparent differences between the adjusted arithmetic averages of the experimental and control groups, and that the adjusted arithmetic average of the control group is (9.10) and the standard error (0.80), while the modified arithmetic average of the experimental group reached (12.88) and the standard error (0.65). In order to verify the statistical significance of the differences between the arithmetic averages of the study sample individuals, an analysis of common variance (ANCOVA) test between the averages was performed, as shown in Table 2.

Table 2. Results of the covariance analysis ANCOVA of students' performance on the practical vocational skills observation card

\begin{tabular}{ccccccc}
\hline$(\eta 2)$ & Sig. & F & Mean squares (MS) & fd & Sum of squares (SS) & Source of variance \\
\hline \multirow{3}{*}{0.32} & 0.17 & 6.31 & 75.86 & 1 & 75.864 & pretest \\
& $0.000^{*}$ & 64.87 & 763.58 & 1 & 763.58 & Group \\
& & & 11.77 & 49 & 577.21 & Error \\
& & & & 51 & 1544.41 & Total \\
\hline
\end{tabular}

\footnotetext{
* Statistically significant at $\alpha=0.05$
} 
Table 2 shows that there are statistically significant differences at the level of significance $(\alpha=0.05)$ between the arithmetic average of the performance for the experimental group students and the arithmetic average of the performance of students of the control group in the practical vocational skills note card, where the value of $F$ was (64.87) and corresponds to the level of significance $(0.00$ These differences came in favor of the experimental group, which was studied according to the strategy based on the concepts of a growth mindset, as shown in Table 1. The value of the effect size using the ETA square $(0.32)$, which is a significant value, indicates that the differences are attributed to the method of teaching using the strategy based on the concepts of a growth mindset. This means that the teaching method has a positive effect in improving the practical vocational skills of students, if it was compared with the usual method.

This result is attributed to the effectiveness of the concepts of the growth mindset itself, as it is based on the idea that intelligence is flexible and can be developed and increased through effort, determination, passion, and the development of personal capabilities, and perhaps this was reflected in the beliefs and concepts that students hold about themselves and their abilities, which positively affected their motivation on and stimulate their interest, and increase their desire to learn. This was confirmed by Dweck (2006), which believes that the mentality of growth encourages a love of learning, especially in difficult situations, which increases the self-efficacy of the student. On the other hand, teaching according to the concepts of a growth mindset is supposed to allow the student to make mistakes in order to obtain learning in the end. This perhaps encouraged students to learn skills without fear of making mistakes, and as a result they have improved practical vocational skills.

Second question: Is there a statistically significant difference at the level of $(\alpha=0.05)$ between the mean scores of the students in the experimental group and the students in the control group in the imaginative thinking scale due to the teaching method(strategy based on concepts of growth mindset, the usual teaching method)?

To answer the study's second question, pre, post, and modified arithmetic averages and standard deviations and adjusted subjects of the study were extracted among the study subjects, as shown in Table 3.

Table 3. Pre, dimensional and modified arithmetic averages, deviations and standard errors of students' performance on testing imaginative thinking skills of the experimental and control groups.

\begin{tabular}{ccccccc}
\hline \multicolumn{2}{c}{ Modified } & \multicolumn{5}{c}{ Post } \\
\hline Standard error & SMA & standard deviation & SMA & standard deviation & SMA & Group \\
77.0 & 10.49 & 2.24 & 11.25 & 2.57 & 9.74 & Control \\
85.0 & 01.15 & 2.82 & 15.97 & 2.12 & 8.93 & Experimental \\
\hline
\end{tabular}

It is clear from Table 3 that there are apparent differences between the modified arithmetic averages of the experimental and control groups, and that the modified arithmetic average for testing the dimensional imaginative thinking skills of the control group is (10.49) and the standard error (0.77), while the modified arithmetic average of the experimental group reached (01.15) and the standard error (0.85). In order to verify the statistical significance of the differences between the arithmetic averages of the study sample individuals, an analysis of common variance (ANCOVA) test between the averages was performed as shown in Table 4.

Table 4. Results of common variance analysis ANCOVA of students' performance on the test of imaginative thinking skills

\begin{tabular}{ccccccc}
\hline$(\eta 2)$ & Sig. & F & Mean squares (MS) & fd & Sum of squares (SS) & Source of variance \\
\hline \multirow{2}{*}{0.27} & 0.11 & 4.31 & 170.98 & 1 & 170.983 & pretest \\
& $* 0.000$ & 21.84 & 283.25 & 1 & 283.246 & Group \\
& & & 12.968 & 49 & 635.456 & Error \\
& & & & 51 & 1135.814 & Total
\end{tabular}

\footnotetext{
* Statistically significant at $\alpha=0.05$
}

Table 4 shows that there are statistically significant differences at the level of significance $(\alpha=0.05)$ between the arithmetic average of the students' performance in the experimental group and the arithmetic average of the students' performance in the control group in the test of imaginative thinking skills, as the value of $\mathrm{F}$ (21.84) corresponds to the level of significance (0.00). These differences came in favor of the experimental group, which was studied according to the strategy of the concepts of the growth mindset, as shown in Table (3). The value of 
the effect size using the ETA square was (0.27), which is a significant value, and indicates that the differences are attributed to the method of teaching, and this means that teaching with a strategy based on the concepts of a growth mindset has a positive effect on improving imaginative thinking skills, if compared to the regular method.

The researcher believes that the use of the concepts of the growth mindset, and the educational activities that it contains, focus on thinking in general, and imaginative thinking in particular. The strategy focused on the student's role in dialogue, consultation, discussion and criticism of opinions about the presented ideas, anticipating events, making assumptions, and imagining what would happen if such a thing happened, and perhaps all of this contributed positively to developing their imaginative thinking skills. The method in which the educational material was presented is based on attracting attention and avoiding stagnation and boredom in regular teaching, which may arouse suspense and love of knowledge among students, and perhaps all of this has a positive effect on imaginative thinking skills. Perhaps the use of the concepts of growth mindset worked to bring the topic of the lesson closer to the level of students 'awareness, as the strategy is mainly based on developing thinking through the conscious transformation of their worldview, and perhaps all of this positively contributed to the development of imaginative thinking skills among students.

\section{Recommendations}

In light of the study results, the researcher recommends the necessity to encourage practical studies teachers to adopt teaching strategies based on the concepts of a growth mindset because of their positive effect on improving practical vocational skills and imaginative thinking among students.

\section{References}

Ayesh, A. (2009). Professional education: What it is, its teaching methods, and its educational applications. Amman: Masirah for Publishing and Distribution.

Bandura, A. (1997). Self-efficacy: The exercise of control. W H Freeman/Times Books/ Henry Holt \& Co.

Bandura, M. M., \& Dweck, C. S. (1985). The relationship of conceptions of intelligence and achievement goals to achievement-related cognition, affect and behavior. Unpublished manuscript. Cambridge: Harvard University.

Duckworth, A. L., Peterson, C., Matthews, M. D., \& Kelly, D. R. (2007). Grit: Perseverance and passion for long-term goals. Journal of Personality and Social Psychology, 92(6), 1087-1101. https://doi.org/10.1037/0022-3514.92.6.1087

Dweck, C. (2015). Mindsets: Developing Talent through A Growth Mindset. Stanford: Stanford University.

Gilman, D. (2008). Effects of Text, Audio, and Graphic Aids in Multimedia Instruction for Vocabulary Learning. Educational Technology \& Society, 11(3), 114-126.

Gonçalves, H., Dias, A., \& Peralta, D. (2018). Comparative study on mathematics teaching in professional education curriculum: Brazil and the United States. Bolema - Mathematics Education Bulletin, 32(60), 31-56. https://doi.org/10.1590/1980-4415v32n60a02.

Khawaldeh, F., \& Nasr, H. (2019). The effectiveness of a proposed strategy based on the integrated listening processes model in improving the imaginative thinking skills of ninth grade female students. Educational Science Studies, 46(1), 153-173.

Kiger, L. (2017). Growth Mindset in the Classroom. Empowering Research for Educators, 1(1). Retrieved from https://openprairie.sdstate.edu/ere/vol1/iss1/4

Lewis, L., Williams, C., \& Dawson, S. (2020). Growth Mindset Training and Effective Learning Strategies in Community College Registered Nursing Students. Teaching and Learning in Nursing, 15(1), 123-127.

Liang, C. (2012). The exploration of indicators of imagination. The Turkish online journal of educational technology, 11(3), 367-374.

Mejia, N. (2019). Strategies for Develping Growth Mindset in a Seventh Grade Mathematics Classroom with Hispanic Students in a Law Socioeconomic Secondary School. Master thesis, California state university channel islands.

Metzlera, J., \& Woessmann, L. (2012). The impact of teacher subject knowledge on student achievement: Evidence from withinteacher within student variation. Journal of Development Economics, 99(2), 486-496. https://doi.org/10.1016/j.jdeveco.2012.06.002 
Qara, S., \& Saifi, A. (2011). Development of creativity and creative people from an integrated perspective. Amman: House of Culture.

Samli, A. (2011). From Imagination to Innovation: New Product Development for Quality of Life. Science \& Media Journal, 2(1), 3-13.

Yeager, D., \& Dweck, C. (2012). Mindsets That Promote Resilience: When Students Believe That Personal Characteristics Can Be Developed. Educational Psychologist, 4 47(4). https://doi.org/10.1080/00461520.2012.722805

Yettick, H. (2016). Mindset in the Classroom: A National Study of K12 Teachers. New York: Research Center.

Zaitoun, H. (2005). Teaching skills. Cairo: The World of Books for Printing, Publishing and Distribution.

\section{Copyrights}

Copyright for this article is retained by the author(s), with first publication rights granted to the journal.

This is an open-access article distributed under the terms and conditions of the Creative Commons Attribution license (http://creativecommons.org/licenses/by/4.0/). 